\title{
Characterization of Prealloyed Ti-6Al-4V Powders from EIGA and PREP Process and Mechanical Properties of HIPed Powder Compacts
}

\author{
Rui-Peng Guo ${ }^{1,2} \cdot$ Lei $\mathrm{Xu}^{2} \cdot$ Bernie Ya-Ping Zong ${ }^{3} \cdot$ Rui Yang ${ }^{2}$
}

Received: 24 August 2016/Revised: 24 October 2016/Published online: 16 February 2017

(C) The Chinese Society for Metals and Springer-Verlag Berlin Heidelberg 2017

\begin{abstract}
Prealloyed Ti-6Al-4V powders were prepared by electrode induction melting gas atomization (EIGA) and plasma rotating electrode process (PREP) in this work. A comparative study of EIGA and PREP powders for hot isostatic pressing (HIPing) compaction was conducted. Characterization of important technological parameters such as particle size distribution, powder surface morphology and flowability was carried out. Microstructure and mechanical properties of Ti$6 \mathrm{Al}-4 \mathrm{~V}$ powder compacts HIPed from EIGA and PREP powders were also investigated. The results showed that the EIGA powder has a finer average particle size and higher tap density, while the PREP powder has better flowability and less pores. Micropores can be observed in heat-treated EIGA powder compacts by X-ray tomography and the porosity was found to be about $0.02 \%$. There are no micropores $(\geq 4 \mu \mathrm{m})$ to be detected in heat-treated PREP powder compacts. Transgranular fracture mode as well as micropores contributes to the scatter in fatigue property of heat-treated PREP powder compacts. The respective advantages and disadvantages of both EIGA and PREP powders for producing Ti-based complex parts through HIPing were also discussed.
\end{abstract}

KEY WORDS: Ti-6Al-4V; Prealloyed powder; Hot isostatic pressing; Near-net shape forming

\section{Introduction}

Titanium and its alloys are attractive for aerospace, chemical and medical applications due to their combination of high specific strength, corrosion resistance, stiffness, fracture and fatigue properties [1-3]. Forging and casting are two conventional methods to produce titanium alloys

Available online at http://link.springer.com/journal/40195

Lei Xu

1xu@imr.ac.cn

1 School of Materials Science and Engineering, Northeastern University, Shenyang 110819, China

2 Institute of Metal Research, Chinese Academy of Sciences, Shenyang 110016, China

3 Key Laboratory for Anisotropy and Texture of Materials, Ministry of Education, Northeastern University, Shenyang 110819, China parts. However, powder metallurgy is also a viable approach to fabricate titanium alloys parts. As well known, compared with steel and aluminum alloys, the extraction and production of titanium are very expensive, and the processing performance of titanium alloys is very poor [4]. In recent years, powder metallurgy techniques have emerged as a cost-efficient way due to the selected near-net shaping (NNS). Titanium alloys parts fabricated through powder metallurgy route can significantly reduce the materials loss and the subsequent machining. It is reported that the coefficient of utilization of raw materials can approach up to approximately $90 \%$ [5].

In general, most parts which can be formed by casting can usually be formed by powder metallurgy route. Recent studies [6-10] have demonstrated that prealloyed powder metallurgy by hot isostatic pressing (HIPing) can fabricate Ti-5Al-2.5Sn, Ti-6Al-4V, Inconel 718 and $\mathrm{Ti}_{2} \mathrm{AlNb}$ powder compacts/components with full density, and mechanical properties of powder compacts are as good as 
that of wrought materials, or better. Therefore, powder metallurgy can be considered as an upgrade of precision casting technology $[11,12]$.

The blended elemental (BE) and prealloyed (PA) techniques are two principle approaches to produce titanium alloy powders, and the BE and PA powders have been used to prepare PM Ti-based alloy components in aerospace application since the 1980s [13]. Compared with BE approaches, the PA powder compacts consolidated by HIPing exhibit better mechanical properties [7]. PREP and EIGA processes are two common PA techniques, which are crucible-free approaches and can produce high-purity powders. In the past 20 years, the most common and only viable method of making high-purity titanium alloy powder with spherical morphology is PREP technique [14].

The aim of this work was to assess the respective advantages of EIGA and PREP Ti-based alloy powders for HIPing application. For this purpose, the EIGA and PREP Ti-6Al-4V powders were used and the detailed powder characteristics, microstructure and mechanical properties of as-HIPed and heat-treated Ti-6Al-4V powder compacts were also investigated.

\section{Experimental Procedures}

\subsection{Materials}

The gas-atomized $\mathrm{Ti}-6 \mathrm{Al}-4 \mathrm{~V}$ powder was made through EIGA technique using a crucible-free system under an argon atmosphere and the PREP Ti-6Al-4V powder was supplied by Shanxi YuGuang Phelly Metal Materials Co. Ltd., Xi' an (China). The detailed powder production process of EIGA and PREP methods were described in Ref. [15]. The chemical compositions of EIGA and PREP Ti$6 \mathrm{Al}-4 \mathrm{~V}$ powders are listed in Table 1. A Mastersizer 2000 laser size analyzer was used to measure particle size fraction distribution of powder. Several feeders with different outlet diameters $(6-10 \mathrm{~mm})$ were used to determine the flowability of powder. Tap densities of EIGA and PREP powders were measured using a capsule with $40 \mathrm{~mm}$ in diameter and $120 \mathrm{~mm}$ in height.

Powders were filled into low carbon steel containers and then vacuum-degassed at $240{ }^{\circ} \mathrm{C}$ for $4 \mathrm{~h}$ at $10^{-3} \mathrm{~Pa}$, sealed and HIPed, as described previously [16]. Both EIGA and PREP powders were hot isostatic pressed at $920-930{ }^{\circ} \mathrm{C}$ and $130 \mathrm{MPa}$ for $3 \mathrm{~h}$. Annealing treatment was carried out for EIGA and PREP powder compacts at $930{ }^{\circ} \mathrm{C}$ for $1 \mathrm{~h}$ followed air cooling, and the aging treatment was conducted at $540{ }^{\circ} \mathrm{C}$ for $8 \mathrm{~h}$, followed air cooling.

\subsection{Microstructural Observations}

The cross-sectional microstructures of powders were observed using an Axiovert 200 MAT optical microscope $(\mathrm{OM})$, and the microstructure for EIGA and PREP powder compacts were observed using an Inspect F50 scanning electron microscope (SEM), after samples were mechanically polished and chemically etched with Kroll's reagent. The fraction of $\alpha$ phase was measured by the image analysis software "Image Pro 6." Five different areas in each sample were used. The powder surfaces and fracture surfaces for tensile and fatigue specimens were also taken by SEM. A VersaXRM-500 X-ray tomography (Micro-CT) was used to map the pore distribution of EIGA and PREP powder compacts after heat treatment. Micro-CT images were obtained with the same voxel of $4 \mu \mathrm{m}$, which means that the 3D visualization of pore size less than $4 \mu \mathrm{m}$ could not be detected. The Micro-CT 3D raw data were analyzed by using an Avizo 8.0 software.

\subsection{Mechanical Tests}

Tensile tests were conducted using a Zwick Z050 testing machine at room temperature. The U-notched Charpy impact tests were conducted on an SAN-ZBC2452-C testing machine. More than three tensile specimens were conducted for each condition, and the average tensile and impact data were used. The high-cycle fatigue (HCF) tests were performed at room temperature in air environment, with a sinusoidal waveform, constant stress amplitude control, a frequency of $\sim 100 \mathrm{~Hz}$, and $R=0.1$. The as-machined surface finish was used for the HCF samples. The dimensions of tensile, impact and HCF testing specimens are shown in Fig. 1.

\section{Results}

\subsection{Powder Characterization}

Figure 2 shows the particle size distribution of EIGA and PREP Ti-6Al-4V powders. Both EIGA powder and PREP

Table 1 Chemical compositions of Ti-6Al-4V powders (wt \%)

\begin{tabular}{llllllllll}
\hline Powder & $\mathrm{O}$ & $\mathrm{N}$ & $\mathrm{H}$ & $\mathrm{Al}$ & $\mathrm{V}$ & $\mathrm{Fe}$ & $\mathrm{Si}$ & $\mathrm{C}$ & $\mathrm{Ti}$ \\
\hline EIGA & 0.110 & 0.001 & 0.001 & 6.05 & 4.04 & 0.05 & 0.05 & 0.03 & Bal. \\
PREP & 0.092 & 0.015 & 0.004 & 5.95 & 4.07 & 0.13 & 0.04 & 0.01 & Bal. \\
\hline
\end{tabular}



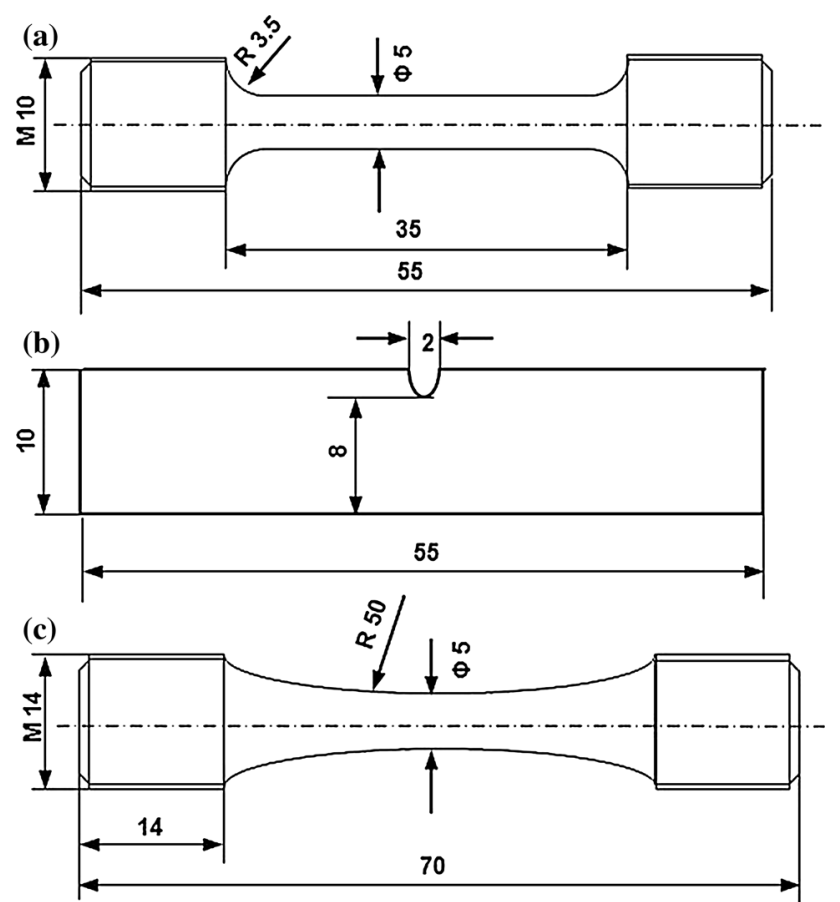

Fig. 1 Geometries and dimensions of specimens for a tensile, b impact, c high-cycle fatigue tests

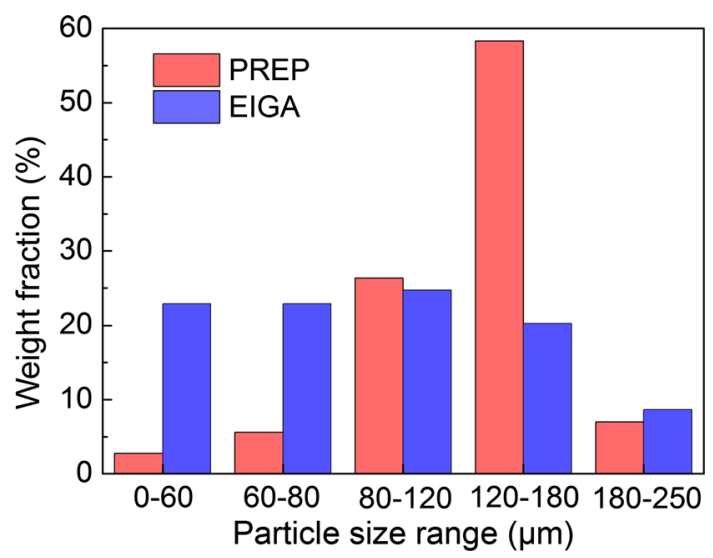

Fig. 2 Particle size distributions of EIGA and PREP Ti-6Al-4V powders

powder were sieved by 60 standard mesh (powder particle size $\leq 250 \mu \mathrm{m}$ ). The EIGA powder distributes extensively in different powder size fractions $(0-60,60-80,80-120$, $120-180$ and $180-250 \mu \mathrm{m}$ ), and the average particle size $\left(d_{50}\right)$ is $93 \mu \mathrm{m}$. The PREP powder is distributed mainly in two powder size fractions (80-120 and 120-180 $\mu \mathrm{m})$, and the average particle size $\left(d_{50}\right)$ is $135 \mu \mathrm{m}$.

Figure 3 shows the particle morphology of EIGA and PREP Ti-6Al-4V powders. The EIGA powder has a nearly spherical shape, and there are some small particles attached to the surface of the large particles, which are called satellites (Fig. 3a). Bear and Merz reported that the satellites would not degrade the tap density during the powder filling [17]. Some imperfect spherical EIGA powders could also be found. However, there is no evidence that the small amount of imperfect spherical powder would affect the densification of the EIGA powder during the HIPing process. According to the SEM images of EIGA powder at high magnification (Fig. 3c), there are some subgrains in EIGA powders resulting in the formation of cellular microstructure, especially in large powder particles. This observed structure of atomized powder is the result of rapid cooling during atomization process [18]. PREP powder is entirely spherical in shape, and the powder surface is rather smooth and free from the satellites (Fig. 3b). The subgrains can only be observed in a small fraction of PREP powders (Fig. 3d). The difference of powder surface morphology may be attributed to the different powder forming techniques (gas and plasma atomization) [19].

Figure 4 shows the cross-sectional microstructure of EIGA and PREP Ti-6Al-4V powders. The microstructures of both EIGA and PREP powders are composed of martensitic $\alpha^{\prime}$ phase due to rapid cooling rate $\left(10^{3}-10^{5} \mathrm{~K} /\right.$ s). Previous works $[11,20]$ have reported the occurrence of gas bubbles (hollow powder with inner gas) in the EIGA powders. Some EIGA powder particles, especially for large ones, tend to contain mores gas bubbles, as shown in Fig. 4a. It is noticed that the PREP powder also has some internal pores after metallographic observations (Fig. 4b), but the volume fraction of porosity in PREP powder is much less than that in EIGA powder, which has also been demonstrated by Ahsan et al. [15] using X-ray tomography. Figure 5 shows the cumulative particle size distribution and the relationship between the frequency of gas bubble and powder size of EIGA powder. It can be seen that the frequency of gas bubble in coarse powders is much higher than that in fine powders.

Tap density and flowability are important technological parameters, which directly affect the densification process. Flowability of EIGA powders with different particle size fractions and outlet diameters of feeders is summarized in Table 2. Figure 6 shows the contour map of flowability of EIGA powder with different particle size fractions and outlet diameters of funnel. It can be seen that the powder with the size fraction of $80-120 \mu \mathrm{m}$ has the best flowability despite the variation of outlet diameter of funnel, and the powder with the fine particle size $(\leq 60 \mu \mathrm{m})$ has the worst flowability. Meanwhile, when the outlet diameter of funnel is $10 \mathrm{~mm}$ or larger, all the powders with different size fractions have an excellent or at least good flowability. When the outlet diameter of funnel is $\sim 6 \mathrm{~mm}$ or less, the flowability of powder (size fraction $\leq 60 \mu \mathrm{m}$ ) is very poor. It is noticed that the as-received EIGA powder with the full 

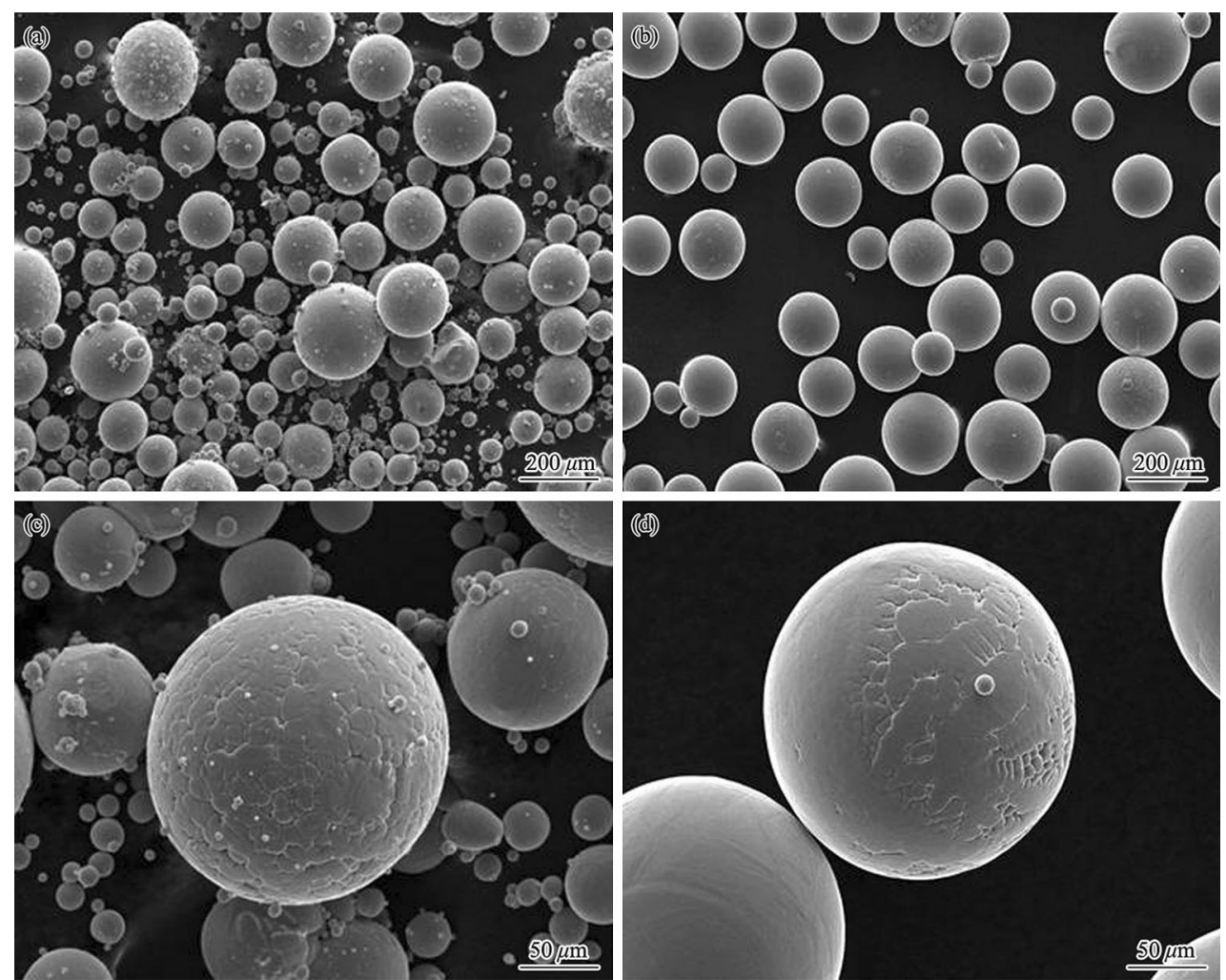

Fig. 3 Ti-6Al-4V powder surfaces: a EIGA, b PREP, $\mathbf{c}, \mathbf{d}$ are higher magnifications of a, b
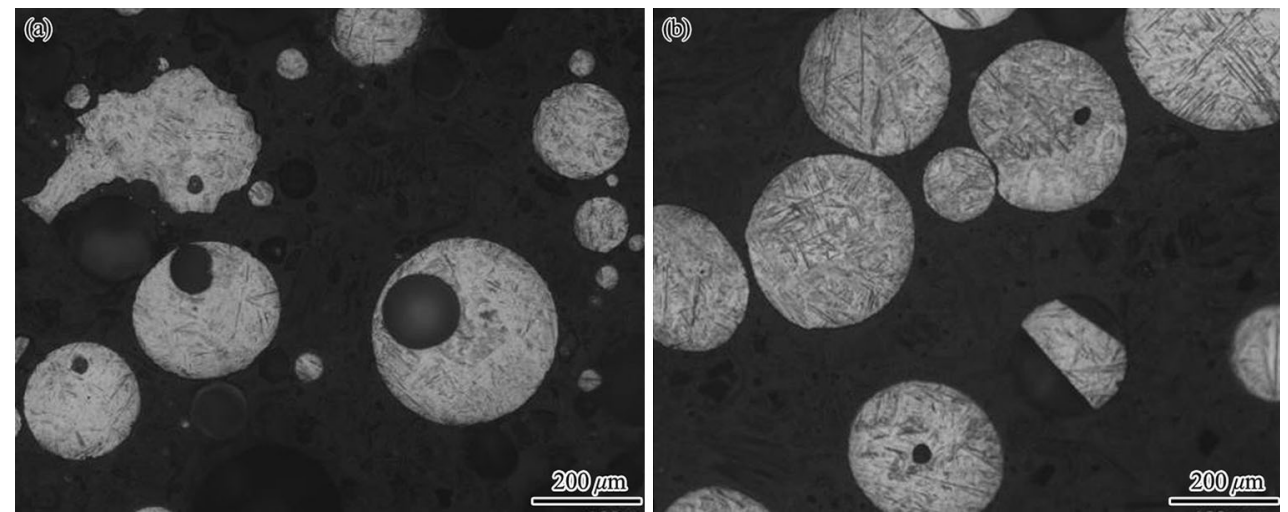

Fig. 4 Cross-sectional microstructure of Ti-6Al-4V powders: a EIGA, b PREP

size fraction $(\leq 250 \mu \mathrm{m})$ also has an excellent flowability (Table 2).

Tap densities of EIGA powder with different particle size fractions are also listed in Table 2. It indicates that the tap density of powder decreases with the increase in the particle size. The EIGA powder $(\leq 60 \mu \mathrm{m})$ has the highest tap density $(\sim 0.664)$ compared with the other powder size fractions. It is noticed that the tap density of EIGA powder with full size fraction is 0.68 . However, the tap density of PREP powder is only 0.64 . The difference in tap density for EIGA and PREP powder $(\leq 250 \mu \mathrm{m})$ is due to the different particle size distribution.

\subsection{Microstructure of Powder Compacts}

Figure 7 shows the microstructure of as-HIPed and heattreated Ti-6Al-4V alloys from EIGA and PREP powders compacts. The microstructures of EIGA and PREP powder compacts are composed of $\alpha$ phase and a little $\beta$ phase. The $\alpha$ grains in as-HIPed and heat-treated powder compacts are lamellar or nearly equiaxed. The equiaxed $\alpha$ grains are generally formed at prior particle surfaces and the $\beta$ phase disperse among the interfaces of the lamellar and equiaxed $\alpha$ phase. The $\alpha$ grains are very fine and disperse uniformly in both as-HIPed and heat-treated EIGA powder compacts 


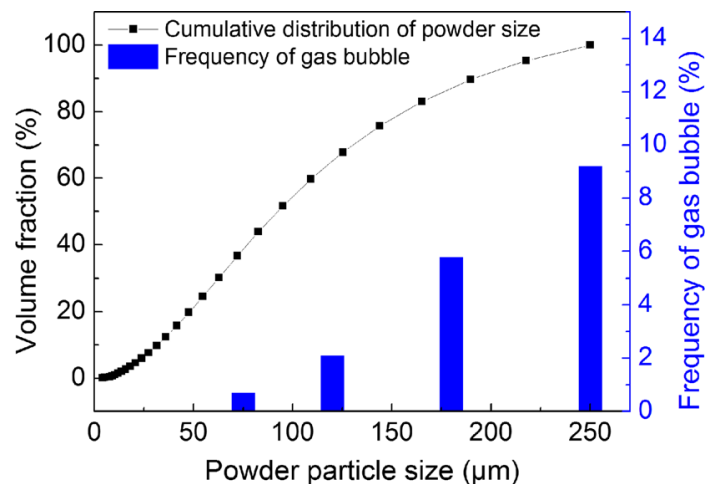

Fig. 5 Cumulative particle size distribution and relationship between the frequency of gas bubble and powder size range for EIGA Ti-6Al$4 \mathrm{~V}$ powder

Table 2 Summary of tap density and flowability of EIGA Ti-6Al$4 \mathrm{~V}$ powders with different powder fractions

\begin{tabular}{lllll}
\hline $\begin{array}{l}\text { Powder fraction } \\
(\mu \mathrm{m})\end{array}$ & $\begin{array}{l}\text { Tap } \\
\text { density }\end{array}$ & \multicolumn{3}{l}{ Flowability $(\mathrm{g} / \mathrm{s})$} \\
\cline { 3 - 5 } & & $\begin{array}{l}\Phi 6 \\
(\mathrm{~mm})\end{array}$ & $\begin{array}{l}\Phi 8 \\
(\mathrm{~mm})\end{array}$ & $\begin{array}{l}\Phi 10 \\
(\mathrm{~mm})\end{array}$ \\
\hline $180-250$ & 0.495 & 10.3 & 18.9 & 58.9 \\
$120-180$ & 0.583 & 13.8 & 23.6 & 71.4 \\
$80-120$ & 0.635 & 17.4 & 26.8 & 96.0 \\
$60-80$ & 0.661 & 6.8 & 9.1 & 45.2 \\
$0-60$ & 0.664 & 5.8 & 7.6 & 36.8 \\
$0-250$ & 0.680 & 12.4 & 19.8 & 67.6 \\
\hline
\end{tabular}

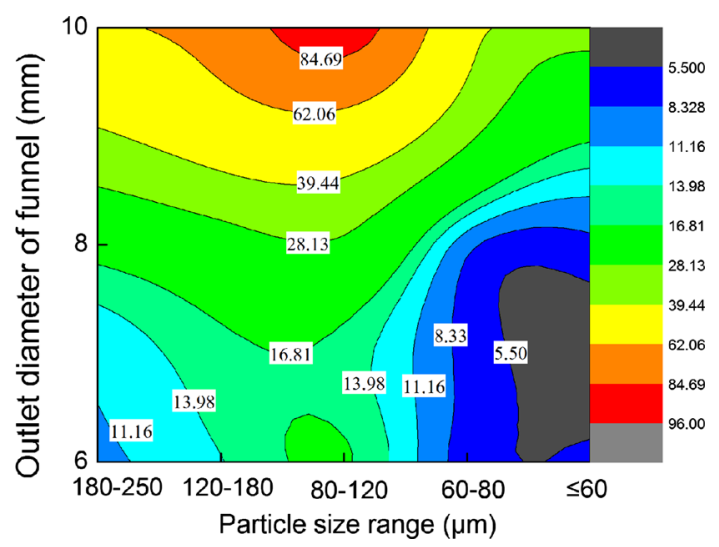

Fig. 6 Contour map of flowability of EIGA Ti-6Al-4V powder

(Fig. 7a, c). The lamellar $\alpha$ grains in PREP powder compacts, which are generally gathered in colonies of more than 10 laths, are much coarser than those of EIGA powder compacts (Fig. 7b, d). The volume fraction of lamellar structure in EIGA and PREP powder compacts is counted on basis of metallographic analysis, and at least 20 fields were investigated. The volume fraction of lamellar structure in PREP powder compact $(\sim 35 \%)$ is much higher than that of EIGA powder compact $(\sim 15 \%)$.
The phase composition and volume fraction of EIGA and PREP powder compacts are given in Table 3. It indicated that the volume fraction of $\beta$ phase for the as-HIPed powder compacts has been improved after heat treatment. The energy-dispersive X-ray (EDX) results show that $\alpha$ phase is enriched with $\mathrm{Al}$ and $\beta$ phase is enriched with $\mathrm{V}$ for both EIGA and PREP powder compacts. The enrichments of $\mathrm{Al}$ in $\alpha$ phase and $\mathrm{V}$ in $\beta$ phase for as-HIPed EIGA powder compact are much higher than those for asHIPed PREP powder compacts due to the higher cooling rate in EIGA powder production process. However, the weight percentage of $\mathrm{Al}$ in $\alpha$ phase and $\mathrm{V}$ in $\beta$ phase is similar in EIGA and PREP powder compacts after duplex annealing heat treatment.

Figure 8 shows the pore distribution of heat-treated EIGA and PREP powder compacts measured by a Micro$\mathrm{CT}$. The pores with different normalized pore size were colored to increase the contrast with the blue matrix. The reconstructed volume was approximately $1.8 \mathrm{~mm} \times 1.8 \mathrm{~mm} \times 1.8 \mathrm{~mm}$. The pore volume fraction of heat-treated EIGA powder compacts calculated by tomographic analysis is only $\sim 0.02 \%$, which cannot be detected by the Archimedes method. However, no pores with size more than $4 \mu \mathrm{m}$ could be found in heat-treated PREP specimens (Fig. 8b).

\subsection{Mechanical Properties of Powder Compact}

Mechanical properties of EIGA and PREP powder compacts are listed in Table 4. It indicates that the tensile properties of EIGA powder compacts are better than those of PREP powder compacts. The fatigue endurance limits of EIGA and PREP powder compacts show similar tendency to the tensile properties. This is mainly because oxygen content in the EIGA powder compact $(\sim 1100 \mathrm{ppm})$ is higher than that of PREP powder compact ( $930 \mathrm{ppm})$, which is consistent with the results of Yan et al. on sintered Ti-6Al-4V [21]. Figure 9 shows the tensile fracture surface of EIGA and PREP powder compacts. It indicates that the fracture surfaces of both EIGA and PREP powder compacts show the characteristics of typical ductile fracture, and dimples spread all over the fracture surfaces.

Figure 10 shows the $S-N$ curves of heat-treated EIGA and PREP powder compacts. It indicates that the maximum applied stress versus cycles to failure of the heat-treated EIGA samples shows a regular trend. However, the fatigue life decreased obviously when the maximum applied stress exceeds the fatigue endurance limit due to the effect of temperature-induced pores caused by the gas bubble, which have been reported in our previous study [11]. However, for heat-treated PREP samples, the fatigue data scatter obviously. Figure 11 shows the fatigue fracture surfaces of heat-treated PREP powder compact. After the fracture 

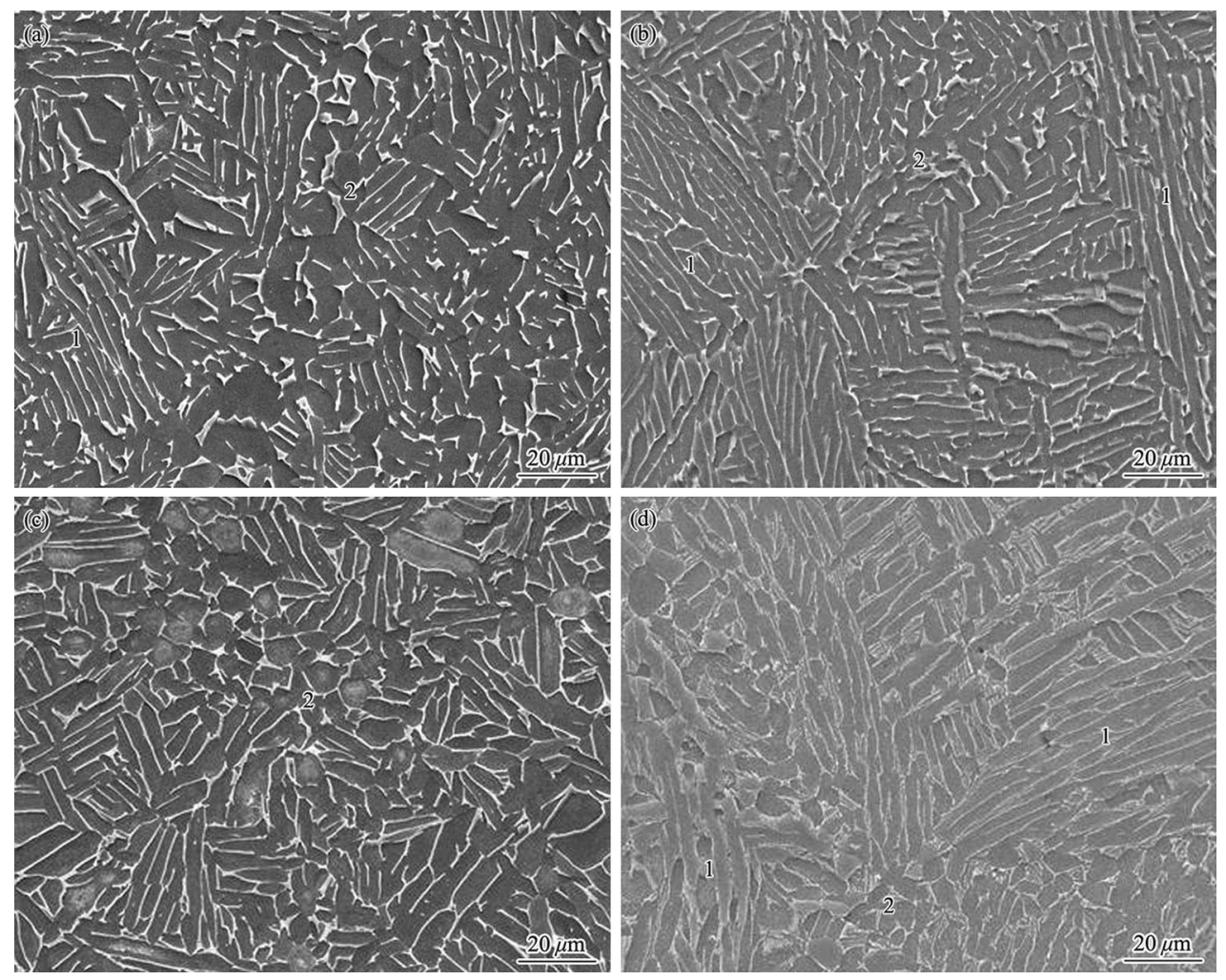

Fig. 7 Microstructure for Ti-6Al-4V powder compacts: a as-HIPed EIGA, b as-HIPed PREP, c heat-treated EIGA, d heat-treated PREP samples. 1 Lamellar $\alpha$ grain gathered in colonies; 2 nodular $\alpha$ grain

Table 3 Phase evolution of Ti-6Al-4V powder compacts after duplex annealing

\begin{tabular}{|c|c|c|c|c|c|}
\hline \multirow[t]{2}{*}{ Condition } & \multirow[t]{2}{*}{ Phase } & \multirow[t]{2}{*}{$V_{\mathrm{p}}(\%)$} & \multicolumn{3}{|l|}{$[M](\mathrm{wt} \%)$} \\
\hline & & & $\mathrm{Ti}$ & $\mathrm{Al}$ & $\mathrm{V}$ \\
\hline \multirow[t]{2}{*}{ EIGA HIPed } & $\alpha$ & 94.1 & $90.7 / 90.7 / 91.6$ & 7.1/7.2/6.6 & $2.2 / 2.1 / 1.8$ \\
\hline & $\beta$ & 5.9 & $77.8 / 80.1 / 82.4$ & $3.7 / 4.7 / 4.2$ & $18.5 / 15.3 / 13.4$ \\
\hline \multirow[t]{2}{*}{ EIGA heat-treated } & $\alpha$ & 84.5 & $91.2 / 90.9 / 90.9$ & $6.9 / 6.8 / 6.9$ & $1.9 / 2.3 / 2.2$ \\
\hline & $\beta$ & 15.5 & $85.5 / 85.6 / 85.1$ & $5.0 / 4.4 / 4.9$ & 9.5/9.9/10.0 \\
\hline \multirow[t]{2}{*}{ PREP HIPed } & $\alpha$ & 95.3 & $90.9 / 91.6 / 91.7$ & $6.2 / 5.6 / 6.2$ & $1.9 / 2.8 / 2.1$ \\
\hline & $\beta$ & 4.7 & $88.1 / 86.2 / 86.5$ & $4.9 / 4.2 / 4.4$ & $6.2 / 9.6 / 9.1$ \\
\hline \multirow[t]{2}{*}{ PREP heat-treated } & $\alpha$ & 87.3 & $91.4 / 90.8 / 91.4$ & $7.2 / 7.4 / 7.1$ & $1.4 / 1.8 / 1.5$ \\
\hline & $\beta$ & 12.7 & $87.8 / 87.8 / 86.7$ & $5.7 / 5.6 / 5.5$ & $6.5 / 6.6 / 7.8$ \\
\hline
\end{tabular}

$V_{\mathrm{p}}$ volume percent, $[M]$ weight percent of the element $M$

surface examinations, for heat-treated PREP samples, six out of ten failed fatigue specimens shows the typical crack initiation sites at the surface and subsurface (Fig. 11a, b). Meanwhile, three out of ten failed fatigue specimens shows transgranular fracture mode (Fig. 11c). Figure 11c also shows that there is a pore with $\sim 25 \mu \mathrm{m}$ in the transgranular facets, and the total cycles to failure $\left(N_{\mathrm{f}}\right)$ is only 427,160 at $\sigma_{\max }$ of $520 \mathrm{MPa}$. Besides, the fatigue life at $\sigma_{\max }$ of $600 \mathrm{MPa}\left(N_{\mathrm{f}}=1,977,904\right)$ is much higher than expected (Fig. 10), and the fracture mode is not a typical subsurface initiation, which is not well understood in this study (Fig. 11d).

\section{Discussion}

EIGA and PREP are two commercial methods to produce high-performance titanium alloys PA powders. For HIPing application, the different characteristics of the microstructure, porosity and mechanical properties of EIGA and 

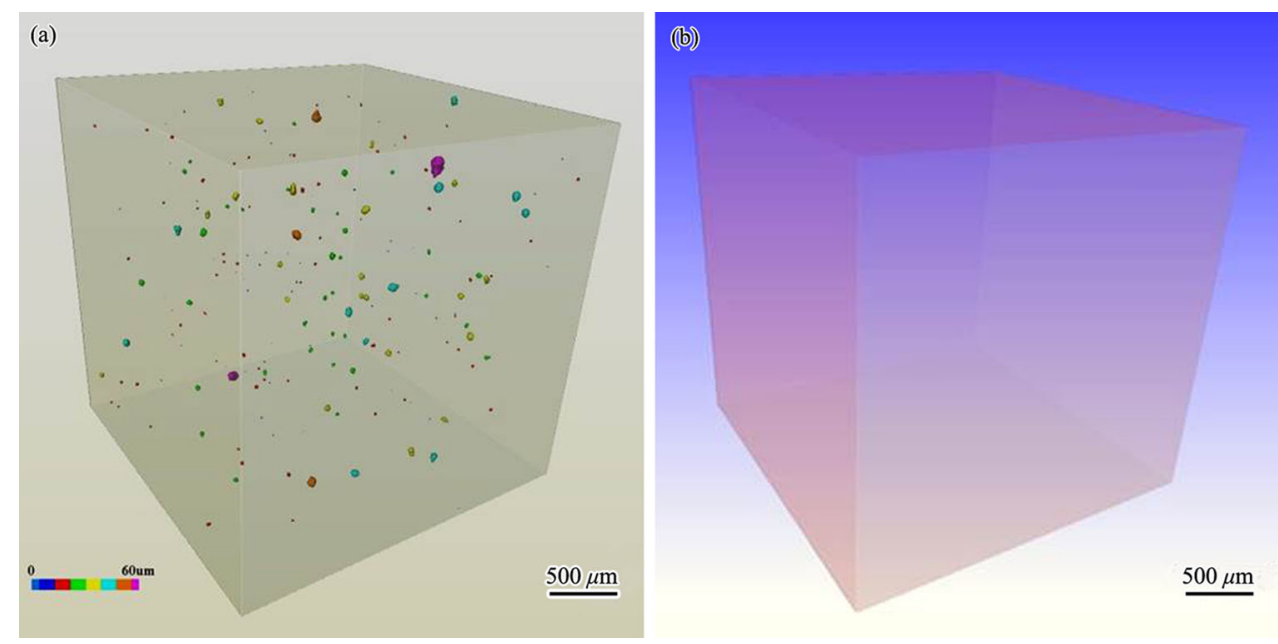

Fig. 8 Micro-CT images for mapping the pore size distribution of a heat-treated EIGA [11], b heat-treated PREP Ti-6Al-4V specimens

Table 4 Room temperature tensile, impact toughness and HCF properties of Ti-6Al-4V powder compacts

\begin{tabular}{|c|c|c|c|c|c|c|c|}
\hline Sample & $E(\mathrm{GPa})$ & $0.2 \%$ Y.S. (MPa) & UTS (MPa) & El. $(\%)$ & R.A. (\%) & $A\left(\mathrm{~kJ} / \mathrm{m}^{2}\right)$ & $\mathrm{HCF}(\mathrm{MPa})$ \\
\hline As-HIPed EIGA & 117 & 849 & 935 & 17.5 & 48 & 580 & $520[11]$ \\
\hline Heat-treated EIGA & 117 & 888 & 995 & 18.5 & 47 & 515 & $540[11]$ \\
\hline As-HIPed PREP & 115 & 834 & 905 & 17.0 & 42 & 680 & NA \\
\hline Heat-treated PREP & 115 & 857 & 944 & 19.5 & 46 & 630 & 510 \\
\hline
\end{tabular}

The number of the tested specimens was 3-6 for each case

Y.S. Yield strength, UTS ultimate tensile strength, R.A. reduction in area, $A$ impact toughness, NA not available

PREP powder compact result from the two different powder production techniques. The discussion will focus on three aspects of the results: (1) powder size distribution, (2) porosity in powder and powder compacts and (3) the influence of microstructure on properties.

\subsection{Powder Size Distribution}

Powder particle size distribution is a crucial powder characteristic, which will influence the powder filling process. Presumably, the differences in powder surface would not influence the flowability for EIGA and PREP powders. According to Fig. 6, the PREP powders are expected to have better flowability than EIGA powder, because the particle size distribution of PREP powder concentrates in the size fraction of $80-180 \mu \mathrm{m}$ (Fig. 2). The EIGA powder has a wide particle size distribution, and the finer particles can occupy the space among the coarse ones during the powder filling/taping. This is helpful to improve the tap density. Therefore, the tap density of EIGA powder (0.68) is higher than that of PREP powder (0.64). As known, the most remarkable advantage of PM-HIP technology is selective near-net shaping compared to the conventional forming processes. Powder filling is a very crucial technological step to bring the capsule to its initial condition prior to HIPing process. High tap density of powder is always preferred to benefit the following powder densification and dimensional control during HIPing. Underfilling may be adverse for the dimensional precision of the NNS parts, especially the large ones [22]. Besides, care must be taken during powder filling to avoid powder size segregation. In particular for the EIGA powder, the gathering of gas bubble and low tap density will occur at the same position of the powder compact.

In our previous study [23], the powder size shows no obvious influence on the tensile properties and rupture life of EIGA Ti-6Al-4V powder compacts. Therefore, the EIGA powder with the size fraction $(60-250 \mu \mathrm{m})$ may be used to produce Ti-based powder compacts for the subsequent thermal mechanical processing or fatigue noncritical powder components, while the EIGA powder with the size fraction $(\leq 60 \mu \mathrm{m})$ can be used for additive manufacturing.

\subsection{Pores in Powders and Powder Compacts}

There are two kinds of pores in the EIGA powder, open pore and closed pore (Fig. 4a). It is believed that the open pore can be healed by the following HIPing process. The 

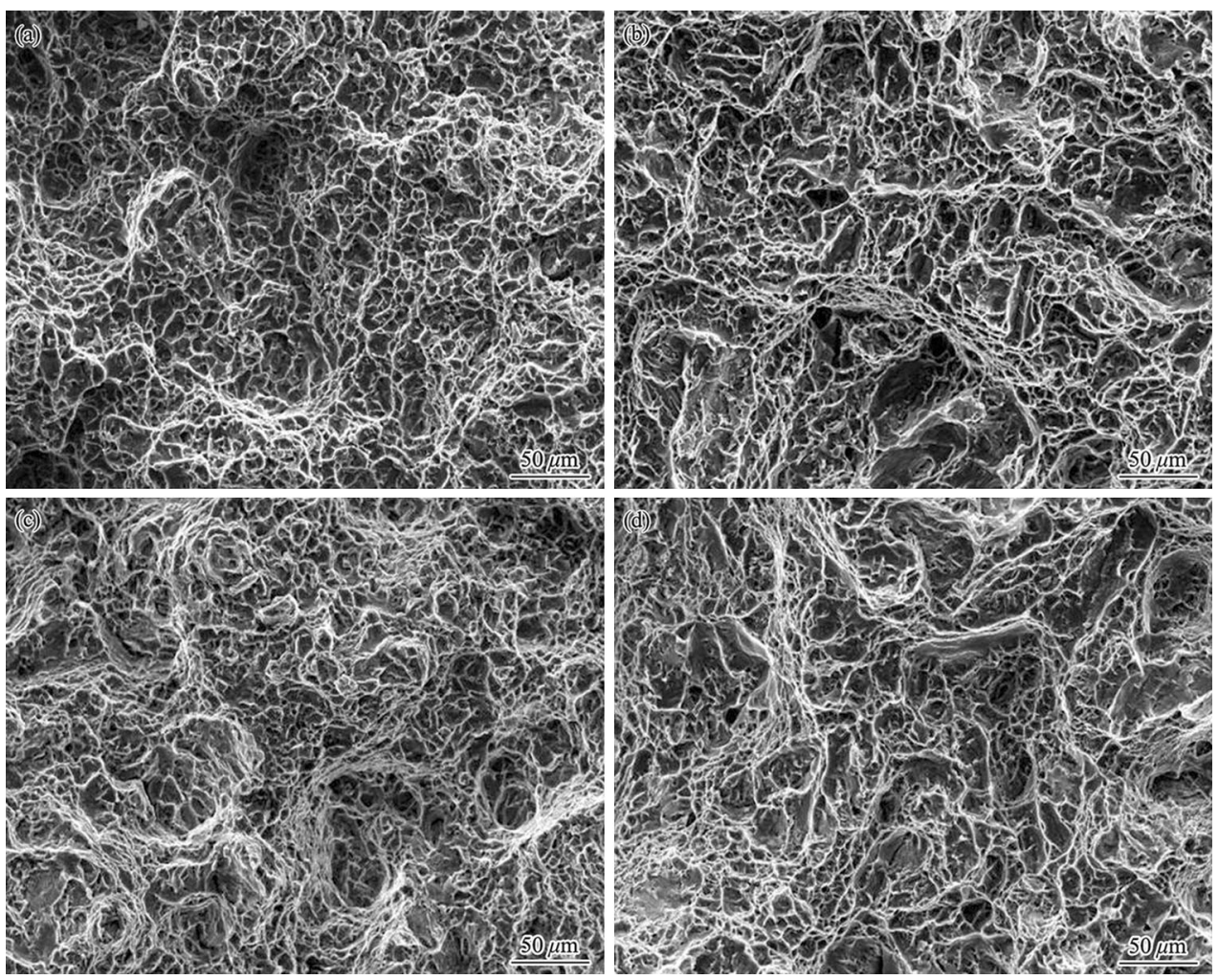

Fig. 9 Tensile fracture surfaces of Ti-6Al-4V alloy: $\mathbf{a}$ as-HIPed EIGA, $\mathbf{b}$ heat-treated EIGA, $\mathbf{c}$ as-HIPed PREP, $\mathbf{d}$ heat-treated PREP specimens

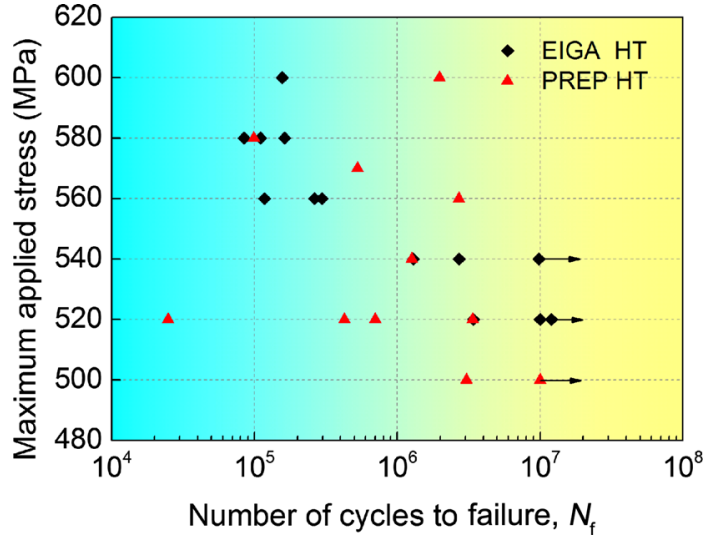

Fig. $10 S-N$ curves for heat-treated Ti-6Al-4V samples. Runout specimens are marked with arrows

closed pore is known as gas bubbles (hollow powder with inner gas), which will affect the final porosity of the HIPed and heat-treated EIGA powder compact [24]. In Fig. 4b, the PREP powder also has a few internal pores; however, the PREP powder compacts contains no pores with size more than $4 \mu \mathrm{m}$ (Fig. 9b). Therefore, the voids of the PREP powder could mostly been healed during HIPing.

Compared with the PREP powder compact, there are many pores in the EIGA powder compacts. However, both the porosity $(\sim 0.02 \%)$ and pore size is very small, and the biggest pore size is less than $60 \mu \mathrm{m}$. The residual porosity in EIGA powder compact is mainly attributed to the gas bubble in EIGA powder. Although the residual porosity ( $\sim 0.02 \%)$ shows no obvious influence on the fatigue endurance limit of heat-treated EIGA powder compact, the hollow powder with gas bubble is still considered as the potential risk of EIGA powder. Future work on the effect of residual porosity on the mechanical properties is of great interest because the existence of pores in EIGA powder compact cannot be avoided.

\subsection{Relationship between the Microstructure and Fatigue Properties}

The fatigue data of the heat-treated PREP samples are very random and distribute across a large range compared with that of EIGA samples. This difference could be correlated with microstructure. The phase compositions, the grain size of EIGA and PREP samples show a little difference, which results in only a little difference in the tensile and impact toughness properties. However, the volume fraction of the lamellar structure of the EIGA powder compact is larger than that of EIGA powder compact. Previous studies figured out that the lamellar structures are generally with the same crystallographic orientation [7,25], which have also been proved in wrought Ti-based alloys [26]. The lamellar structure with the 

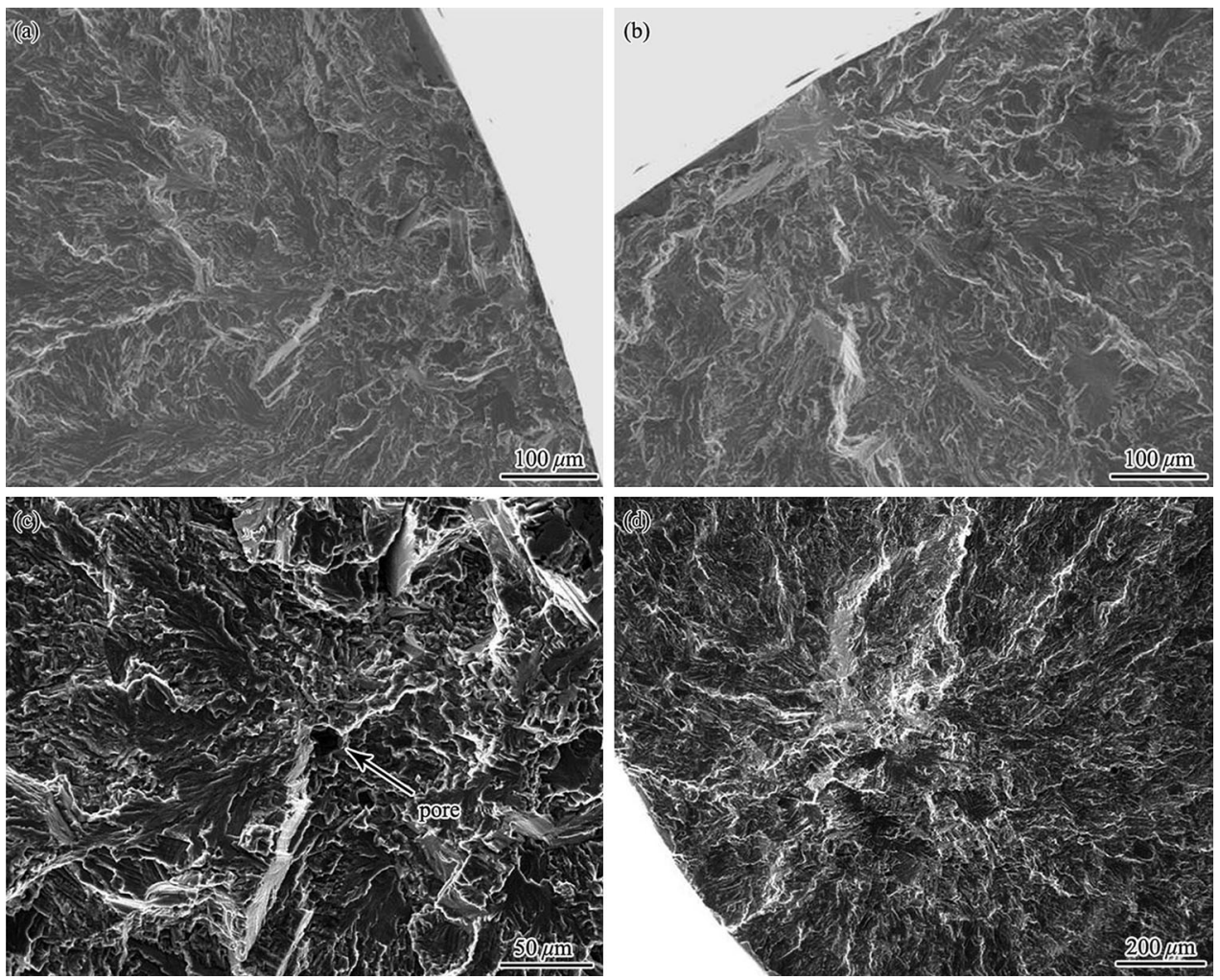

Fig. 11 Fatigue fracture surface of heat-treated PREP Ti-6Al-4V samples: a $\sigma_{\max }=520 \mathrm{MPa}, N_{\mathrm{f}}=3,374,525, \mathbf{b} \sigma_{\max }=560 \mathrm{MPa}$, $N_{\mathrm{f}}=2,695,330, \mathbf{c} \sigma_{\max }=520 \mathrm{MPa}, N_{\mathrm{f}}=427,160, \mathbf{d} \sigma_{\max }=600 \mathrm{MPa}, N_{\mathrm{f}}=1,977,904$

similar crystallographic orientations may be the crack initiation site during the fatigue tests. Besides, the $\beta$ phase layers are very thin (Fig. 7). Therefore, the slip bands can easily form across the entire lamellar structure, leading to transgranular fracture mode. Based on fatigue facture analysis, three out of ten failed fatigue specimens shows transgranular fracture surface and the responding fatigue life is very short.

In the present study, the fatigue strength is not available. Previous studies reported that the fatigue endurance limit (at $10^{7}$ cycles) of the as-HIPed PREP samples is in the range of 350-450 $\mathrm{MPa}[7,27]$, which is much lower than that of EIGA samples.

\section{Conclusions}

(1) EIGA powder has a finer average powder size and higher tap density, while the PREP powder has better flowability and less porosity.

(2) Volume fraction of lamellar structure in PREP powder compact is much higher than that of EIGA powder compact. Micro-CT results showed that the porosity of heat-treated EIGA powder compacts is about $0.02 \%$, but no pores $(\geq 4 \mu \mathrm{m})$ can be detected in heat-treated PREP powder compacts.
(3) No obvious difference is found on the static mechanical properties of EIGA and PREP powder compacts. The transgranular fracture mode for fatigue specimens could be attributed to the lamellar structure in PREP powder compacts. The transgranular fracture mode as well as micropores contributes to the scatter of fatigue lives of heat-treated PREP powder compacts.

Acknowledgement This work was partially supported by the National Key Research and Development Program of China (No. 2016YFB0701200).

\section{References}

[1] R.R. Boyer, Mater. Sci. Eng. A 213, 103 (1996)

[2] C. Leyens, M. Peters, Titanium and Titanium Alloys (Wiely, Weinheim, 2003)

[3] J.C. Williams, E.A. Starke, Acta Mater. 51, 5775 (2003)

[4] L. Bolzoni, E.M. Ruiz-Navas, E. Gordo, Mater. Sci. Eng., A 609, 266 (2014)

[5] Z.Z. Fang, Sintering of Advanced Materials: Fundamental and Processes (Woodhead Publishing Limited, Cambridge, 2010)

[6] R.P. Guo, L. Xu, W.X. Cheng, J.F. Lei, R. Yang, Acta Metall. Sin. 52, 842 (2016)

[7] K. Zhang, J. Mei, N. Wain, X. Wu, Metall. Mater. Trans. A 41, 1033 (2010) 
[8] L. Chang, W. Sun, Y. Cui, R. Yang, Mater. Sci. Eng., A 599, 186 (2014)

[9] J. Wu, L. Xu, Z.G. Lu, B. Lu, Y.Y. Cui, R. Yang, J. Mater. Sci. Technol. 31, 1251 (2015)

[10] F.H. Froes, S.J. Mashl, V.S. Moxson, J.C. Hebeisen, V.A. Duz, JOM 56, 46 (2004)

[11] R.P. Guo, L. Xu, J. Wu, R. Yang, B.Y. Zong, Mater. Sci. Eng. A 639, 327 (2015)

[12] R. Yang, Acta Metall. Sin. 51, 129 (2015)

[13] F. Cao, K.S. Ravi Chandran, P. Kumar, P. Sun, Z. Zak Fang, M. Koopman, Metall. Mater. Trans. A 47, 2335 (2016)

[14] G. Lütjering, J.C. Williams, Titanium (Springer, Berlin, 2007)

[15] M.N. Ahsan, A.J. Pinkerton, R.J. Moat, J. Shackleton, Mater. Sci. Eng. A 528, 7648 (2011)

[16] L. Xu, R. Guo, C. Bai, J. Lei, R. Yang, J. Mater. Sci. Technol. 30, 1289 (2014)

[17] D.R. Bear, M.D. Merz, Metall. Mater. Trans. A 11, 1973 (1980)

[18] A.M. Birt, V.K. Champagne, R.D. Sisson, D. Apelian, Adv. Powder Technol. 26, 1335 (2015)
[19] G. Yablokova, M. Speirs, J. Van Humbeeck, J.P. Kruth, J. Schrooten, R. Cloots, F. Boschini, G. Lumay, J. Luyten, Powder Technol. 283, 199 (2015)

[20] G. Wegmann, R. Gerling, F.P. Schimansky, Acta Mater. 51, 741 (2003)

[21] Y. Yan, G.L. Nash, P. Nash, Int. J. Fatigue 55, 81 (2013)

[22] V. Samarov, D. Seliverstov, F.H. Froes, in Titanium Powder Metallurgy: Science, Technology and Applications, ed. by Q. Ma, F.H. Froes (Butterworth-Heinemann, Oxford, 2015)

[23] R.P. Guo, L. Xu, B. Zong, R. Yang, Mater. Des. 99, 341 (2016)

[24] B.H. Rabin, G.R. Smolik, G.E. Korth, Mater. Sci. Eng. A 124, 1 (1990)

[25] S. Di Iorio, L. Briottet, E.F. Rauch, D. Guichard, Acta Mater. 55, 105 (2007)

[26] R.K. Nalla, B.L. Boyce, J.P. Campbell, J.O. Peters, R.O. Ritchie, Mater. Trans. A 33, 899 (2002)

[27] C. Cai, B. Song, P. Xue, Q. Wei, J. Wu, W. Li, Y. Shi, J. Alloys Compd. 686, 55 (2016) 